\title{
Araştırma
}

\section{İnsidental Saptanan Karaciğer Kist Hidatiği Sıklığı: Endemik Bölgelerde Karın Ağrılı Olgularda USG Gerekliliği}

\author{
FREQUENCY OF INCIDENTAL HEPATIC HYDATID CYST: REQUIREMENT OF ULTRASOUND IN \\ CASES WITH ABDOMINAL PAIN IN ENDEMIC REGIONS
}

\section{Gülşen ÇIĞŞAR ${ }^{1}$, Şahin KAHRAMANCA ${ }^{2}$, Emsal AYDIN ${ }^{3}$, Mahmut DUYMUŞ ${ }^{4}$, Çağlar Bülent BİLGİN ${ }^{5}$, Murat ÖZDEMİR ${ }^{1}$, Fatih Mehmet AVŞAR ${ }^{5}$}

${ }^{1}$ Kafkas Üniversitesi Tıp Fakültesi Acil Tıp Anabilim Dalı

2Sağlık Bakanlığı Kars Devlet Hastanesi Genel Cerrahi Kliniği

${ }^{3}$ Kafkas Üniversitesi Tıp Fakültesi Enfeksiyon Hastalıkları Anabilim Dalı

${ }^{4}$ Gazi Üniversitesi Tıp Fakültesi Radyoloji Anabilim Dalı

${ }^{5}$ Kafkas Üniversitesi Tıp Fakültesi Genel Cerrahi Anabilim Dalı

\begin{abstract}
ÖZ
Amaç: Karaciğer Kist Hidatiği (KKH), daha çok gelişmekte olan ülkelerde görülen zoonotik enfeksiyondur. Hastaların çoğu asemptomatik olmasına karşın, nadiren bası bulguları ve karın ağrısı yakınmaları da olabilir. Tanı sıklıkla çeşitli radyolojik yöntemler yardımıyla konur.

Yöntemler: Acil servise karın ağrısı yakınması ile başvuran ve acil abdomen Ultrasonografisi (USG) yapılan hastaların dosya kayıtlarından yaş, cinsiyet, USG sonuçları, KKH saptanan hastalardaki KKH bulunan karaciğer segmenti ve KKH Gharbi sınıflamasına göre tipi kayıt altına alındı. Kist hidatik varlığı, karaciğer kisti saptanan kişilerde elektif şartlarda yapılan İndirekt Hemaglütinasyon Testi (IHAT) ile doğruland1.

Bulgular: Hastaların 96'sında $(\% 4,5) \mathrm{KKH}$ ve bu hastaların 7 'sinde basıya bağlı mekanik ikter saptandı. KKH saptanan hastaların yaş ortalaması 47,4 \pm 19,3 idi. Kadın/erkek oranı $70 / 26$ olup $\mathrm{KKH}$ kadınlarda daha yüksek oranda saptandı $(p<0,001)$. KKH insidental olarak en fazla sağ lobda $(\% 70,8)$ ve en fazla segment 8 ve 7 'de $(\% 30,2$ ve $\% 19,8)$ saptandı. Gharbi sinıflamasına göre $K K H$, sıklık sirasına göre tip $4(\% 35,4)$, tip3 (\%26,0), tip2 (\%17,7), tip5 (\%11,5) ve tip1 (\%9,4) saptand.

Sonuç: KKH açısından endemik sayılan bölgelerde, özellikle üst kadran ağrısı ile acile başvuran hastalardan KKH anamnezleri olmasa da, ayrıntılı anamnez, sistemik fizik bakı ve rutin yardımcı tanı yöntemleri sonrası tanı konulamadığında abdominal USG istenmesi, özellikle bizim bölgemizdeki gibi yaklaşık her 22 hastadan 1'inde KKH saptanmasını sağlayabilmektedir. Bu oran, tolere edilebilir maliyet ve iş gücüne neden

olmakla birlikte erken tanı konulan olgularda, olası komplikasyonları engelleyerek morbidite ve mortalite oranlarını azaltabilir.

Anahtar sözcükler: Karaciğer kist hidatiği, insidental, Gharbi sınıflaması

ABSTRACT

Objective: Hepatic Hydatid Cyst (HHC) is a zoonotic infection, more common in developing countries. Most of the patients are asymptomatic, but rarely, signs of comp-
\end{abstract}

\section{Gülşen ÇıĞŞAR}

Kafkas Üniversitesi

Tip Fakültesi

Acil Tıp Ana Bilim Dalı

KARS

Makalemizin özeti 2014'te Antalya'da düzenlenen 19. Ulusal Cerrahi Kongresi'nde poster bildirisi olarak sunulmuştur.

(C) 2014 DEÜ TIP FAKÜLTESİ DERGISİ

CiLT 28, SAYI 2, (AĞUSTOS) 2014, 63 - 67 
ression and abdominal pain could be seen. Diagnose is usually made by the help of some radiological methods.

Methods: The medical files of the patients were scanned who admitted to emergency department of our hospital with abdominal pain, and diagnosed HHC after urgent abdominal ultrasound. Age, gender, ultrasound results, HHC type, the liver segment with $\mathrm{HHC}$ of the patients whom detected $\mathrm{HHC}$ were recorded.

Results: HHC was detected in 96 patients $(4.5 \%)$, and there were icterus in 7 patients due to compression. Average age of patients with $\mathrm{HHC}$ was $47.4 \pm 19.3$. HHC was found a higher proportion in women with $70 / 26$ female/male ratio $(p<0.001)$. Most of the incidental $\mathrm{HHC}$ was found in right lobe (70.8\%) and segments 8 and $7(30.2 \%$ and $19.8 \%)$. The frequency of HHC according to Gharbi classification were detected as type4 $(35.4 \%)$, type3 $(26.0 \%)$, type2 $(17.7 \%)$, type $5(11.5 \%)$, type1 $(9.4 \%)$.

Conclusion: Requesting abdominal ultrasound from the patients who admits to emergency department with especially upper abdominal pain, after getting detailed medical history, systemic physical examination, and routine diagnostic procedures even if they don't have HHC anamnesis, in endemic regions, should enable detecting HHC in every 1 patient out of 22 . This ratio causes tolerable cost and workforce as well as decreasing mortality and morbidity rates of the early diagnosed cases by preventing complications.

Keywords: Hepatic hydatid cyst, incidental, Gharbi classification

Karaciğer Kist Hidatiği (KKH), daha çok gelişmekte olan ülkelerde ve hayvancılıkla uğraşan toplumlarda sik rastlanılan ve echinococcus granulosus ve echinococcus multilocularis adı verilen sestodlarla bulaşan zoonotik enfeksiyondur. Hastalık, insanlara kesin konak olan enfekte köpeklerin dışkıları ile kirlenmiş yiyeceklerdeki yumurtaların alınması ile bulaşmaktadır (1). Karaciğer ve akciğer en sık tutulan organlardır. Hastaların çoğu asemptomatik olmasına karşın, nadiren bası bulguları, nonspesifik karın ağrısı yakınmaları da olabilir (2). Tanı sıklıkla insidental olarak çeşitli radyolojik yöntemler yardimiyla konur.

Çalışmamızda, KKH için endemik sayılan bölgelerde karın ağrısı yakınması ile acil servise başvurup herhangi bir patoloji saptanamayan ve yapilan acil abdomen ultrasonografi sonucunda hastalarda kist hidatik saptanma sıklığını ve ultrasonografi gerekliliğini ortaya koymayı amaçladık.

\section{YÖNTEM}

Helsinki Deklarasyon kriterlerine uygun olarak, Ocak 2010 - Temmuz 2013 tarihleri arasında Kafkas Üniversitesi Tıp Fakültesi ve Kars Devlet Hastanesi Acil Servislerine karın ağrısı yakınması ile başvuran ve acil abdomen Ultrasonografisi (USG) yapılan 2437 hastanın dosya kayıtları retrospektif tarandı. Dosya kayıtlarından yaş, cinsiyet,
USG sonuçları, KKH saptanan hastalardaki KKH bulunan karaciğer segmenti ve KKH Gharbi sınıflamasına göre kist tipi kayıt altına alındı (Gharbi sınıflaması açılaması Tablo I'de verilmiştir). Kist hidatik varlığı, karaciğer kisti saptanan kişilerde elektif şartlarda yapılan İndirekt Hemaglütinasyon Testinde (İHAT) 1/360 ve üzeri titreler anlamlı kabul edilerek doğrulandı (3). Karaciğer kist hidatiği saptanan hastalar Grup 1, saptanmayan hastalar Grup 2 olarak ayrıldı. Gruplar arasında yaş ve cinsiyet analizi yapıldı. Daha önceden KKH öyküsü olduğu bilinen, elektif bakılan İHAT sonucu negatif çıarak basit kist tanısı konulan ve dosya verilerine ulaşılamayan 299 hasta çalışma dışı bırakıldı.

\section{İSTATİSTIKSEL ANALİZ}

Verilerin analizi SPSS for Windows 17 (Chicago, İL, USA) paket programında yapıldı. Sürekli değişkenlerin dağılımının normale yakın olup olmadığı Kolmogorov Smirnov testiyle araştırıldı. Tanımlayıcı istatistikler sürekli değişkenler için ortalama \pm standart sapma veya ortanca (minimum-maksimum) olarak kategorik değişkenler ise olgu sayısı ve (\%) şeklinde gösterildi. Gruplar arasında ortalamalar yönünden farkın önemliliği Mann Whitney U testi ile incelendi. Kategorik değişkenler Pearson'un KiKare testiyle değerlendirildi. $p<0,05$ için sonuçlar istatistiksel olarak anlamlı kabul edildi. 
Tablo I. Karaciğer kist hidatiğinde Gharbi sınıflaması

\begin{tabular}{lr}
\hline Gharbi Sınıflaması & Pür kistik \\
\hline Tip I & Membran ayrışması içeren kistik oluşum \\
Tip II & Multiple septa ve kız vezikülleri içeren kist, araba tekerleği görünümü \\
Tip III & Yüksek internal eko, hiperekoik heterojen solid kitle görünümü \\
Tip IV & Kalsifiye kalın duvarlı kist \\
Tip V & \\
\hline
\end{tabular}

\section{BULGULAR}

Çalışmamıza dahil edilen 2138 hastada yaş için median değer 50 (min:10, max:101) olup kadın/erkek oranı 1,74 idi. Hastaların 96'sında (\%4,5) KKH ve bu hastaların 7'sinde basıya bağlı mekanik ikter saptandı. KKH saptanan hastalarda yaş için median değer 47 (min:10, max: 85) olup gruplar arasındaki yaş dağılımının homojen olduğu tespit edildi $(p=0,204)$. Kadın / erkek oranı 70/26 olup $\mathrm{KKH}$, kadınlarda daha yüksek oranda saptanmış idi $(p<0,001)$. KKH insidental olarak en fazla sağ lobda $(\% 70,8)$ ve en fazla segment 8 ve 7 'de $(\% 30,2$ ve $\% 19,8)$ saptandı (Tablo II). Gharbi sinıflamasına göre KKH tipleri, sıklık sırasına göre tip $4(\% 35,4)$, tip3 $(\% 26,0)$, tip2 $(\% 17,7)$, tip5 $(\% 11,5)$ ve tip1 $(\% 9,4)$ olarak saptandı (Tablo III).

Tablo II. KKH'li hastalarda kistin karaciğer yerleşim yeri

\begin{tabular}{lr}
\hline Karaciğer segmenti & n $(\%)$ \\
\hline Segment 1 & $2(2,1)$ \\
Segment 2 & $4(4,2)$ \\
Segment 3 & $8(8,3)$ \\
Segment 4 & $14(14,6)$ \\
Segment 5 & $8(8,3)$ \\
Segment 6 & $12(12,5)$ \\
Segment 7 & $19(19,8)$ \\
Segment 8 & $29(30,2)$ \\
\hline
\end{tabular}

Tablo III. Gharbi sınıflaması

\begin{tabular}{lr}
\hline Gharbi sinıflaması & n (\%) \\
\hline Tip 1 & $9(9,4)$ \\
Tip 2 & $17(17,7)$ \\
Tip 3 & $25(26,0)$ \\
Tip 4 & $34(35,4)$ \\
Tip 5 & $11(11,5)$ \\
\hline
\end{tabular}

\section{TARTIŞMA}

$\mathrm{KKH}$, kesin konağı köpek, ara konağı insan olan ve hayvancılıkla uğraşılan bölgelerde endemik olarak görülen bir helmint enfestasyonudur. Görülme sıklı̆̆ı ülkeler ve aynı ülke içinde bölgeler arasında değişkenlik göstermektedir. Özellikle Kuzey Afrika ve Ortadoğu ülkeleri gibi gelişmekte olan ülkelerde sıktır. Genelde klinik bulgu vermez ve insidental olarak saptanır. Sağlık Bakanlığı ülkemizde 100.000 'de 4,4 oranında KKH saptandı̆̆ 1 verisini bildirmiştir (4). Çalışmamızda, acile karın ağrısı yakınması ile başvuran ve KKH olduğu bilinmeyen hastalarda yap1lan abdomen USG sonucunda, KKH için endemik sayllabilecek şehrimizde her 22 hastanın birinde KKH saptandığı ve KKH'a bağlı olası gelişebilecek komplikasyonları engeleme adına endemik kabul edilen bölgelerde herhangi bir patoloji saptanmayan karın ağrılı olgularda USG yapılması gerekliliği sonucuna ulaştık.

Çalışmamıza dahil edilen hasta sayısı, retrospektif olarak planladığımız çalışmamızdan çıkan sonucun güvenilirliğini kanıtlayacak kadar yüksek volümdedir. Ayrıca çalışmanın planlandığı şehir olan Kars ilinin de KKH için endemik sayılabilecek bölgeler arasında bulunması çalışmamızın bir diğer güçlü tarafıdır.

$\mathrm{KKH}$, genellikle hayat boyu sessiz kalan bir enfestasyon türüdür. Sıklıkla karaciğer sağ lobda ve soliter yapıdadır (5). Çalışmamızda da KKH olgularının \%72,9'u $(n=70)$ karaciğer sağ lobda yerleşim göstermiştir. Bunun nedeninin, karaciğer sağ lobunun kütlesel büyüklüğüne ve portal venin karaciğer sağ lobuna direkt açılmasına, sol loba açılı dökülmesine bağlı olabileceğini düşünmekteyiz.

KKH'ın yılda yaklaşık 1-3 cm çapta büyüme hızı olduğu bildirilmiştir (6). Kliniği son derece sessiz seyreden $\mathrm{KKH}^{\prime}$ da, varolan ancak atlanan kist olgusu, birkaç yıl 
içinde bası bulgusu verebilecek boyutlara ulaşarak özellikle genç yaşta, $>10 \mathrm{~cm}$ büyüklükte ve yüzeyel lezyonlarda perforasyonlara ve mekanik ikter gibi komplikasyonlara yol açabilmektedir (7). Literatürde komplikasyon oranları \%1,7-8,6 arasında bildirilirken, özellikle rüptür durumlarında \%25'lere varan mortalite oranları da bildirilmiştir $(8,9)$. Acil servisimize başvuran hastalardaki kist boyutu $38 \mathrm{~mm}$ (min:7 mm, max: $159 \mathrm{~mm}$ ) olarak ve hastaların 7'sinde bası bulgusuna bağlı makenik ikter saptand1. Mekanik ikter saptanan hastalara operasyon öncesi Endoskopik Retrograd Kolanjio Pankreatografi (ERCP) uygulandı. Akyıldız ve ark KKH saptanan olgulardaki ortalama kist çaplarını 5-100 mm arasında saptanmıştır. Bu da bizim verilerimize uygundur (1).

\%51-77 oranında kadın cinsiyet hakimiyetinin belirtildiği literatürde KKH için görülme yaş ortalaması 36-47 arasında bildirilmiştir $(5,10)$. En genç hastamızın 10, en yaşlı hastamızın da 85 yaşında olduğu çalışmamızda median yaş; literatürle benzer özellikte olarak 47 olarak saptanmış olup, hayvancılıkla uğraşan kırsal bölgelerde kadınların hayvanlarla daha sık temasta olması nedeniyle $\mathrm{KKH}, \% 72,9$ oranında kadın cinsiyette daha baskın olarak görülmüştür.

Kist hidatik tanısı, çalışmamızın da konusunu oluşturduğu gibi sıklıkla insidental olarak konulur. En eski yardımcı tanı yöntemi olan USG ya da tomografik yöntemlerle kistik lezyonu kuşkusu olan hastada, indirekt hemaglütinasyon testi $1 / 360$ ve üzeri titrelerde olduğunda tanı konulmaktadır $(3,11)$. Çalışmamızda da USG'de KKH kuşkusu olan tüm hastalara elektif şartlarda İHAT bakılarak tanı doğrulanmıştır.

Kist hidatik özellikle hayvancılığın sık yapıldığı bölgelerde endemik sayılabilecek kadar sık görülen bir halk sağlığı sorunudur. İstanbul Adli Tıp Kurumu Morg Dairesince yapılan 1687 otopside $34 \mathrm{KKH}(\% 2,0)$ saptanmıştır. Ülkemizde kırsal alanlarda farklı tarihlerde yapılan $\mathrm{KKH}$ sıklığı ile ilgili epidemiyolojik çalışmalarda, 100 binde 585 ve 100 binde 291 sıklıkta KKH olgusu saptanmıştır $(12,13)$. Sümer ve ark da ülkemizde bu oranı 100 binde 1,3 olarak bildirmiştir (14). Ülkemizin farklı bölgelerindeki 2-4 yıllık sürelerde KKH sıklığını bildiren Şahin ve ark; Trakya'da 5.1/100000, İzmir'de 3.2/100000, Adana'da 11.8/100000, Şanlıurfa'da 3.3/100000, Erzurum'da 2.1/100000,
Samsun'da 2/100000, Malatya'da 2.3/100000, Kayseri'de $10.6 / 100000$ ve Samsun'da 2/100000 insidansta oran bildirmişlerdir (15). Çalışmamızda karın ağrısı yakınması olan hastalarda \%4,5 oranında insidental olarak $\mathrm{KKH}$ saptanmıştır.

\section{SONUÇ}

$\mathrm{KKH}$ açısından endemik sayılan bölgelerde, özellikle üst kadran ağrısı ile acile başvuran hastalardan $\mathrm{KKH}$ anamnezleri olmasa da, ayrıntılı anamnez, sistemik fizik bakı ve rutin yardımcı tanı yöntemleri sonrası tanı konulamadığında abdominal USG istenmesi, özellikle bizim bölgemizdeki gibi yaklaşık her 22 hastadan 1'inde $\mathrm{KKH}$ saptanmasını sağlayabilmektedir. Bu oran, tolere edilebilir maliyet ve iş gücüne neden olmakla birlikte erken tanı konulan olgularda, olası komplikasyonları engelleyerek morbidite ve mortalite oranlarını azaltılabilir.

\section{KAYNAKLAR}

1. Akyıldız EÜ, Yılmazer Ö, Üzün İ ve ark. Adli otopsilerde saptanan hidatik kistler. Adli Tıp Dergisi 2006;20:30-34.

2. Larrieu EJ, Frider B. Human cystic echinococcosis: contributions to the natural history of the disease. Ann Trop Med Parasitol, 2001;95:679-687.

3. Topçu AW, Söyletir G, Doğanay M ve ark. Enfeksiyon hastalıkları ve mikrobiyolojisi, 2008;3:1137.

4. WHO/OIE Manual on Echinococcosis in Humans and Animals: a Public Health Problem, chapter 4 Geographic distribution and prevalence p.107.

5. Albayrak D, Sezer YA, İbİş AC, Yağcı MA, Hatipoğlu AR, Coşkun İ. Karaciğer Kist Hidatik Olgularımız. Trakya Universitesi Tıp Fakültesi Dergisi 2008;25:95-99.

6. Sayek İ, Tirnaksız MB, Doğan R. Cystic Hydatid Disease: Current trends in diagnosis and management. Surg Today, 2004; 34: 987-996.

7. Barnes SA, Lillemoe KD. Liver abscess and hydatid cyst disease. In Maingot's abdominal operations 1997;10: 1513-1545.

8. Bülbüller N, Ilhan YS, Kirkil C, Yeniçerioğlu A, Ayten $R$, Cetinkaya $Z$. The results of surgical treatment for hepatic hydatid cysts in an endemic area. Turk J Gastroenterol 2006;17:273-278.

9. Ozturk G, Aydinli B, Yildirgan MI, et al. Posttraumatic free intraperitoneal rupture of liver cystic echinococcosis: 
a case series and review of literature. Am J Surg 2007; 194:313-316.

10. Açıkgöz D, İnceboz T, Özkara E, Korkmaz M, Birgen N, Üzün İ. İstanbul Adli Tıp Kurumu Morg İhtisas Dairesi'nde Yapılan Otopsilerde Kistik Ekinokokkozis Görülme Sıklı̆̆ının Arastırılması. Türkiye Parazitoloji Dergisi 2009; 33:155-157.

11. Gharbi HA, Hassine W, Brauner M, Dupuch K. Ultrasound examination of the hydatic liver. Radiology 1981; 139:459-463.

12. Alkan MZ, Özcel MA. Kist hidatikte sero-epidemiyolojik arastırmalar, Türkiye Parazitol Dergisi, 1994;18:302-307.
13. Altıntas N, Yazar S, Yolasıgmaz A, Akısü Ç, Sakru N, Karacasu F. A seroepidemiological study of Cystic Echino-coccosis and surrounding area. Helmintologia, 1999;36:19-23.

14. Bostan H, Yücel AF, Şahin A. Ameliyat sırasında oluşan şokun nadir bir sebebi: Karaciğer hidatik kist rüptürüne bağlı anaflaksi. Olgu sunumu. Journal of Surgical Arts 2010;3:12-15.

15. Şahin İ, Yılmaz H, Gödekmerdan A ve ark. Değişik illerde Kistik Echinococcosis'in (Hidatidoz) Son Durumu (2-3 yıllık veriler). 12. Ulusal Parazitoloji Kongresi 2001; 41-50. 